\title{
Mecanismos socioecológicos e práticas tradicionais de pesca na comunidade caiçara da Ilha Diana (Santos, Brasil) e suas transformações *
}

\section{Socio-ecological mechanisms and traditional fishery practices at the Ilha Diana caiçara community (Santos, Brazil) and their transformations}

\author{
Fernanda Terra Stori ${ }^{\circledR, 1}$, Nivaldo Nordi ${ }^{1}$, Denis Moledo de Souza Abessa ${ }^{2}$
}

\section{RESUMO}

Aspectos de resiliência e sustentabilidade nos sistemas socioecológicos para adaptação aos momentos de crise vêm sendo amplamente discutidos na comunidade científica. Escolhemos analisar o caso da comunidade caiçara da Ilha Diana (município de Santos, Brasil), que se manteve relativamente isolada do mundo comercial até aos dias de hoje e agora passa por grandes transformaçóes devido à poluição estuarina, ao declínio da pesca artesanal e à expansão do complexo industrial-portuário sobre seu território. Discutimos neste artigo quais os elementos que configuram adaptatividade e resiliência na comunidade da Ilha Diana para que ela possa promover sustentabilidade neste sistema socioecológico. Concentramos este estudo na identificação qualitativa dos aspectos da cultura caiçara, mecanismos sociais e práticas tradicionais de manejo dos recursos pesqueiros e suas transformaçóes. Através de uma abordagem etnoecológica foram entrevistadas 20 pessoas ( $9 \%$ da população residente), com idades variando de 18 a 90 anos, respeitando-se a equidade entre gêneros. Uma entrevistada experiente respondeu a uma entrevista aberta sobre a história da comunidade, história da pesca e práticas tradicionais de manejo pesqueiro. Os demais entrevistados responderam a questionários semi-estruturados. Cinco entrevistados que se declararam pescadores ativos (42\% dos pescadores ativos na Ilha Diana) também responderam a um questionário sobre práticas tradicionais de manejo pesqueiro. Foram identificados aspectos genuínos da cultura caiçara no território da Ilha Diana, o principal deles é sua organização social interligada à pesca e o auto-reconhecimento desta cultura, o que reforça o caráter tradicional desta comunidade, conforme relatam autores como Diegues (1983) e Begossi et al. (1998). Identificamos sete práticas de manejo baseadas no conhecimento ecológico local e quatro mecanismos sociais atrelados às práticas conforme preconizado por Folke et al. (1998). Ainda, foram identificadas três inovaçóes pesqueiras relacionadas à transferência geográfica de conhecimento e a perda de uma prática sustentável de pesca (cerco fixo) devido à imposição de políticas públicas vertical-descendentes. As transformações decorrentes do desenvolvimento econômico no território da Ilha Diana, como a expansão portuária, têm feito com que os habitantes da Ilha Diana abandonem a pesca e procurem novas formas de obter renda, ocasionando a perda intergeracional de conhecimento ecológico e dos mecanismos sociais atrelados - fato que poderá diminuir a resiliência neste sistema socioecológico. Entretanto, mecanismos sociais ainda existentes como a identidade enquanto caiçaras, reciprocidade, relaçóes familiares, tradiçóes religiosas e a habilidade na reorganizaçáo diante de momentos de crise, poderão contrabalançar aspectos negativos do processo de mudança e crise, promovendo a reorganização do sistema. A habilidade dos habitantes da Ilha Diana em interagir com a da sociedade comercial e a flexibilidade de tais interaçóes são fatores que podem elevar a resiliência deste sistema socioecológico.

Palavras-chave: Ecologia Humana; Cultura, Expansão Portuária, Resiliência Socioecológica.

@- Corresponding author

1 - Universidade Federal de São Carlos, São Carlos. Rodovia Washington Luiz, Km 235, Monjolinho, Caixa Postal 676, CEP 13.565-905, Säo Carlos-SP, Brasil.e-mails: Stori-feterra@terra.com.br; Nordi-nivaldo@ufscar.br.

2 - Universidade Estadual Paulista "Júlio de Mesquita Filho". Campus Experimental do Litoral Paulista. Praça Infante Dom Henrique, s/n. Parque Bitaru, São Vicente, SP, Brasil. e-mail: dmabessa@clp.unesp.br 


\section{ABSTRACT}

Aspects of resilience and sustainability in social-ecological systems to adapt to moments of crisis have been widely discussed in the scientific community. We chose to analyze the case of traditional caiçara community of Ilha Diana (Santos municipality, Brazil) that has been isolated of the commercial world until nowadays and now it passes through a considerable transformation due to the estuarine pollution, to the decline of artisanal fishery and to the expansion of the Santos' industrial-port complex in this territory. In this paper we discuss which elements configure adaptability and resilience at Ilha Diana caiçara community, in order to promote sustainability in this social-ecological system. We focused this study in the identification of the aspects of caiçara culture, social mechanisms and the traditional practices of fishery resources management and their transformations. Through an ethnoecological approach, 20 inhabitants were interviewed (9\% of the resident population), with ages between 18 and 90 years old and respecting the gender equity. One female expert answered an open interview about the history of the community, the history of the local fishing and about traditional fishery management practices. The others interviewees answered to a semi-structured questionnaire. Five of this interviewees, that declared itself currently fishermen (42\% of the currently fishermen in Ilha Diana), also answered a questionnaire of traditional fishery management practices. Genuine aspects of caiçara culture were identified, mainly its social organization linked to fishery and the self-recognition of this culture, which endorse the traditional feature of this community as indicated by authors as Diegues (1983) ans Begossi et al. (1998). We also identified seven management practices based on the local ecological knowledge and four social mechanisms connected to those practices as proposed by Folke et al. (1998). Furthermore we identified three fishery innovations related to the geographical knowledge transmission and the loss of a sustainable fishery practice due to the imposition of vertical-descendent public policies. The changes in ecosystem induced by the economical development in Ilha Diana territory, as port expansion are making the inhabitants to abandon fishery and search new forms to obtain income, leading to the intergenerational loss of ecological knowledge and the loss of the social mechanisms linked to it - factor that can decrease resilience in this social-ecological system. However, the maintenance of come social mechanisms that can still be found, as their identity as caiçara, reciprocity, family relationship, religious tradition and the ability of re-organization before moments of crisis, can counterbalance to the negative aspects of changes and crisis, promoting the re-organization of the system. The ability of Ilha Diana inhabitants to interact with the commercial society and the flexibility of its interactions are elements that can increase the resilience in this socialecological system.

Keywords: Human Ecology; Culture; Port expansion; Social-ecological Resilience.

\section{INTRODUÇÃO}

O termo caiçara tem origem no vocábulo tupi-guarani caá-içara, o homem do litoral (Sampaio, 1987 citado em Adams, 2000). Para estes povos, o termo era utilizado para denominar as estacas colocadas à volta das tabas ou aldeias e o curral feito de galhos de árvores para cercar os peixes. Com o passar do tempo, passou a ser o nome dado às palhoças construídas nas praias para abrigar as canoas e os petrechos de pesca. Mais tarde passou a ser utilizado para identificar o morador de Cananéia e daí para todos os indivíduos e comunidades do litoral dos estados do Paraná, São Paulo e Rio de Janeiro (Adams, 2000). As comunidades caiçaras são formadas pela miscigenação de indígenas, colonizadores portugueses e, em menor escala, de escravos africanos (Diegues, 1983).

A comunidade da Ilha Diana é uma dessas comunidades, reconhecida no município de Santos pela atividade pesqueira artesanal e manutenção do modo de vida caiçara, porém ainda sem o reconhecimento legal de seu território (Stori, 2010). Hoje, seus moradores estão presenciando um novo desafio à sua tradição. Em 2006 um empreendimento portuário privado recebeu do Instituto Brasileiro do Meio Ambiente e dos Recursos Naturais Renováveis - IBAMA - a Licença de Instalação para aterrar e construir em uma área de 803.000 $\mathrm{m}^{2}$ sobre o manguezal, território de pesca da comunidade da Ilha Diana. A implantação deste empreendimento portuário pode desestabilizar o patamar de sustentabilidade no sistema socioecológico desta comunidade caiçara.

Conforme publicado no documento Agenda 21 brasileira (Ministério do Meio Ambiente, 2002) programas de expansão portuária são por si só, açôes de grande impacto ambiental para a regiáo costeira. Essas obras têm como função dotar os estados de infraestrutura necessária para a instalação ou incremento de parques industriais, cujas atividades beneficiam a economia dos estados em uma escala macro. Porém, os impactos econômicos, ecológicos e sociais desses empreendimentos na escala micro, ou seja, numa escala que inclui as populaçóes tradicionais pesqueiras que habitam a zona costeira, deveriam ser tratados com muito mais interesse e importância, ao considerar essas açôes por um prisma do desenvolvimento sustentável.

Considerando que a expansão portuária, a poluição do estuário e a supressão dos manguezais, possam gerar grandes transformaçóes nos territórios tradicionais de pesca, perguntamo-nos: quais elementos configuram adaptatividade e resiliência na comunidade da Ilha Diana para que ela possa se adaptar às iminentes transformaçóes e promover sustentabilidade neste sistema socioecológico?

De modo a responder à questáo postulada, este estudo objetivou: (1) A identificação dos aspectos da cultura caiçara que se fazem presentes na comunidade da Ilha Diana - aspectos relacionados à religião, ancestralidade, auto-reconhecimento como caiçaras, relaçôes familiares, organização social; (2) A identificação de suas práticas tradicionais de manejo baseadas no conhecimento tradicional sobre a pesca, e mecanismos sociais atrelados; e (3) A análise das transformaçóes e adaptaçóes deste modo de vida e território ao longo do tempo.

Justificamos a importância de proceder à identificação dos aspectos socioecológicos e das práticas tradicionais de manejo dos recursos naturais em comunidades tradicionais, a fim de fornecer subsídios para discussóes em resiliência e sustentabilidade em sistemas socioecológicos. 


\section{MÉTODO}

\section{1. Área de Estudo}

A Ilha Diana localiza-se na outra margem do rio que a separa do terminal portuário em construção, entre as coordenadas geográficas $23^{\circ} 54^{\prime} 56.84^{\prime \prime}$ S. e $46^{\circ} 18^{\prime} 30.13^{\prime \prime}$ O. Apesar do nome a tal ilha situada em área de manguezal se forma esporadicamente de acordo com a variação da maré e está delimitada pelo canal de Bertioga e o rio Diana estando o rio Sandi mais a oeste, rios sistema estuarino e de áreas alagadas da Baixada Santista.

A Ilha Diana possui cerca de 240 residentes e, de acordo com informaçôes obtidas na comunidade, aproximadamente metade são crianças. As residências localizam-se à beira do Rio Diana, um braço do sistema estuarino e de áreas alagadas da Baixada Santista, onde predominam manguezais e florestas altas de restinga, ecossistemas inseridos no bioma
Mata Atlântica. Não há estradas que levem à Ilha Diana, sendo que a vila isola-se do continente esporadicamente, conforme a amplitude das marés.

De acordo com o Instituto Brasileiro de Geografia e Estatística (IBGE), que realiza o censo populacional no Brasil e disponibiliza as informaçóes de cada cidade em seu portal electrónico (IBGE Cidades@), o município de Santos possui aproximadamente 410 mil habitantes (IBGE, 2010), e se desenvolveu historicamente atrelado ao setor portuário. -De acordo com o resumo das movimentações de cargas no Porto de Santos ${ }^{1}$ o Porto de Santos movimentou mais de 97 milhóes de toneladas no ano de 2011 e por ele passam $55 \%$ do PIB e $49 \%$ da produçáo nacional entre

1 - Disponíveis no portal internet do porto de Santos (http://www.portodesantos.com.br/)
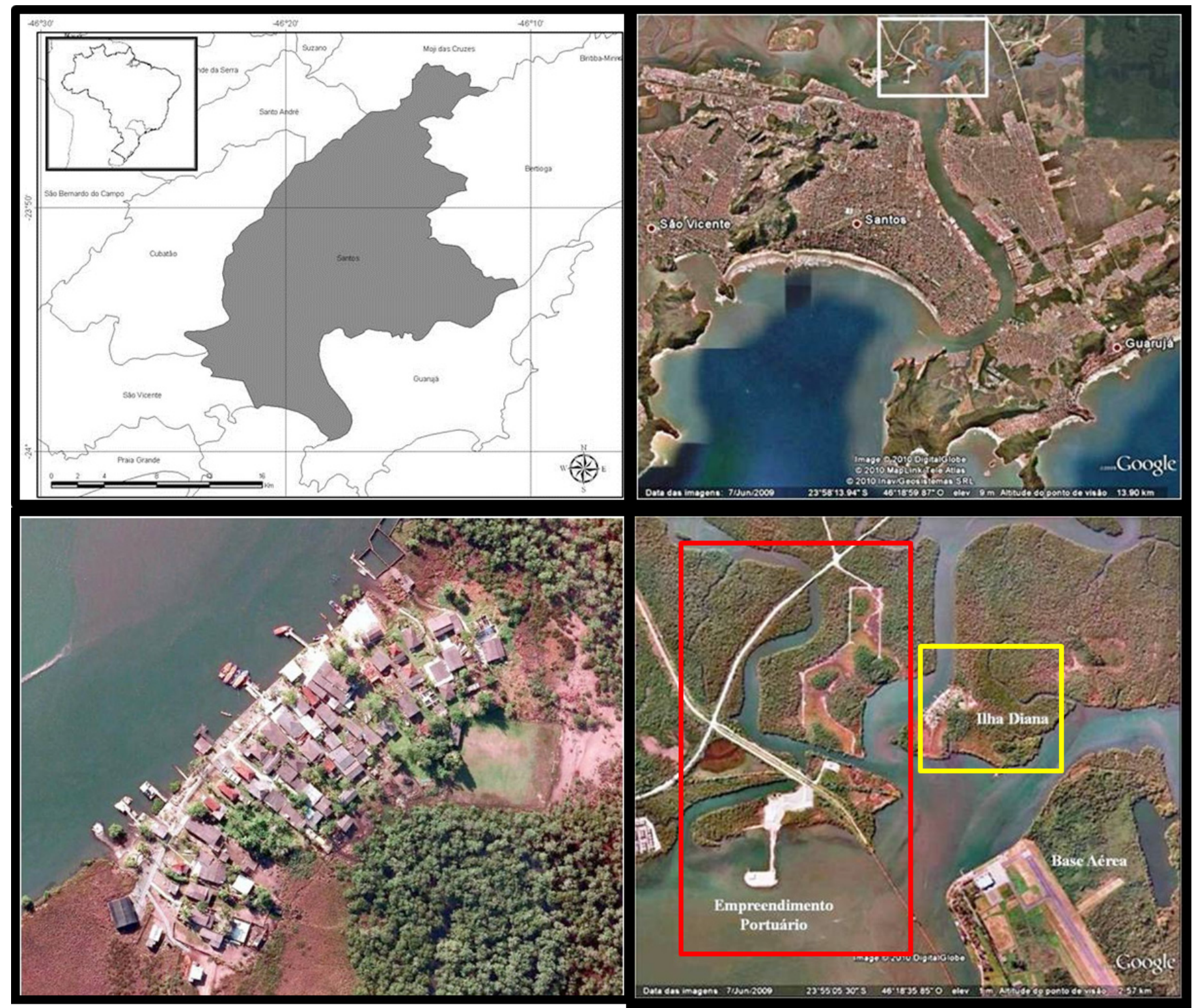

Figura 1. Localização da comunidade de Ilha Diana e do empreendimento portuário no estuário de Santos - SP, Brasil. (Fonte: Google Earth, 2010).

Figure 1. Location of Ilha Diana community and the port enterprise in the Santos' estuary - SP, Brazil. (Source: Google Earth, 2010). 
produtos agrícolas e industriais, como: álcool, açúcar, soja, fertilizantes, óleo diesel, sucos cítricos, trigo, carne, café, sal e GLP (gás liquefeito de petróleo). De acordo com o ranking mundial de movimentação de contêineres elaborado pela revista britânica Conteinerisation Internacional, o Porto de Santos ocupou o $30^{\circ}$ lugar em 2011 com a movimentaçáo de 2.985.922 Teus (unidade de medida equivalente a um contêiner de 20 pés).

$\mathrm{O}$ crescimento da regiáo trouxe riquezas, mas gerou também diversos passivos ambientais, entre eles, destaca-se a poluição das águas estuarinas, sedimentos e organismos aquáticos, provocada pela combinação de fontes múltiplas, como o porto, as indústrias, os lixốes e aterros industriais, esgotos, entre outros (Lamparelli et al., 2001; Abessa et al., 2008). Para Afonso (1999), a Baixada Santista de fato se destaca como a área mais comprometida de toda a zona costeira paulista, com suas águas, solo, ar e matas, contaminados pelas atividades industriais, portuárias e pelo lançamento de efluente doméstico não tratado. Outro problema histórico é a ausência de planejamento do uso do solo, que provocou a supressão de extensas áreas de florestas de manguezais e restingas e permitiu a instalação de empreendimentos portuários, aterros, desvios e assoreamento de canais estuarinos, além da invasấo de ocupaçôes irregulares (Lamparelli et al., 2001; Tommasi, 1979; Afonso, 1999).

O terminal portuário em discussão está sendo instalado sobre uma área de 803 mil metros quadrados de manguezal e restinga, classificada no Plano Diretor Municipal como Zona Portuária (Prefeitura Municipal de Santos, 1998). Espera-se que quando concluído, o terminal com $1100 \mathrm{~m}$ de extensão, receba simultaneamente até 8 navios e tenha capacidade para movimentação anual de 1,2 milhão de contentores (ou contêineres), 200 mil veículos, 2 milhóes de toneladas de granéis sólidos vegetais e até 5 milhões de metros cúbicos de granéis líquidos, principalmente álcool. Estima-se a geração de cerca de mil empregos diretos e outros 1,1 mil indiretos (EMBRAPORT, 2003).

\subsection{Consideraçóes teóricas sobre a abordagem utilizada}

De acordo com Diegues (1983) o modo de vida caiçara baseia-se nas estreitas relaçôes familiares, tendo como base econômica as atividades de pesca e o desenvolvimento de uma agricultura itinerante, além de atividades de extrativismo vegetal. Isolados dos grandes centros urbanos, os caiçaras mantiveram suas tradiçóes e costumes que incorporam um grande conhecimento dos recursos naturais locais. A partir da década de 50 , com a construção das primeiras rodovias interligando litoral e planalto, essas comunidades começaram a enfrentar as dificuldades para manutençáo de sua forma tradicional de vida (Diegues, 1983). De acordo com este autor, a economia caiçara, apesar de baseada na pequena produção de mercadorias, possui características capitalistas.

A agricultura exerceu um papel importante entre os caiçaras até aproximadamente 1950, quando começou a ser superada, enquanto fonte de renda pela pesca. $\mathrm{O}$ baixo preço pago pela mandioca em relação à pesca explica essa mudança econômica (Diegues, 1983; Begossi et al., 1998), sendo esta última a principal fonte de renda de muitas comunidades caiçaras do litoral. A mudança de produtividade da agricultura para a pesca entre os caiçaras, como resposta a pressóes de mercado ocorridas na década de 1950, aumentou suas chances de sobrevivência. Os indivíduos que se envolveram em atividades pesqueiras, na maior parte artesanal, apresentaram um desempenho econômico melhor e foram seguidos por outros membros da comunidade.

Para Begossi (1998), tanto os caiçaras quanto os caboclos, estão inseridos em sociedades neotradicionais ou sistemas neotradicionais de manejo de recursos. A autora define esse sistema como os que apresentam tanto elementos de sistemas tradicionais, como de sistemas recentes e emergentes e possuem diferentes graus de interação com a sociedade. Nesse contexto as populações neotradicionais são as que possuem tanto conhecimentos tradicionais quanto uma bagagem de novos conhecimentos provenientes de fora.

Os caiçaras receberam especial atenção quando da promulgação da Política Nacional de Desenvolvimento Sustentável dos Povos e Comunidades Tradicionais -PNPCT-, em fevereiro de 2007 (Presidência da República do Brasil, 2007), a qual tem por objetivo "promover o desenvolvimento sustentável dos Povos e Comunidades Tradicionais, com ênfase no reconhecimento, fortalecimento e garantia dos seus direitos territoriais, sociais, ambientais, econômicos e culturais, com respeito e valorização à sua identidade, suas formas de organização e suas instituições".

De acordo com o Art. 3, Inciso I da PNPCT (Presidência da República do Brasil, 2007), "Povos e Comunidades Tradicionais" são "grupos culturalmente diferenciados e que se reconhecem como tais, que possuem formas próprias de organização social, que ocupam e usam territórios e recursos naturais como condição para sua reprodução cultural, social, religiosa, ancestral e econômica, utilizando conhecimentos, inovaçooes e práticas gerados e transmitidos pela tradição".

Esta Política define ainda que "Territórios Tradicionais" são "espaços necessários à reprodução cultural, social e econômica dos povos e comunidades tradicionais, sejam eles utilizados de forma permanente ou temporária”. Salientamos a importância de assegurar o direito ao território às populaçóes tradicionais como meio fundamental de conservar a cultura e citamos Rappaport (1982, apud Marques, 2001), que afirma que a cultura é o meio pelo qual as populaçóes se mantêm nos ecossistemas.

Begossi (1998) acredita que comportamentos culturais podem influenciar a resiliência ecológica. Há o comportamento humano flexível, como o da adaptação às mudanças climáticas, e o comportamento conservador e refratário, como em algumas comunidades tradicionais, fenômeno denominado inércia cultural (Boyd \& Richerson, 1985 citado em Begossi, 1998). A inércia cultural pode deixar de ser útil ao ecossistema ou, ao contrário, contribuir para elevar a resiliência do sistema socioecológico ao prevenir a sobrexploração de sistemas ou auxiliar na sua recuperação (Begossi, 1998).

De acordo com Begossi (1998), a cultura caiçara se mostra menos adaptável às novas situaçóes quando comparada com a cultura dos caboclos amazônicos (devido à grande diversidade de ecossistemas produtivos na floresta amazônica). Begossi verificou em seu estudo que os caiçaras sempre estiveram ligados ao sistema econômico da região e continuamente vem modificando suas estratégias adaptativas e comportamentos 
econômicos para sua sobrevivência, ao mesmo tempo que pequenas mudanças podem ser observadas no dia-a-dia. A autora acredita que a fronteira flexível dessas comunidades pode diminuir sua inércia cultural e torná-las mais acessíveis a novos valores culturais, o que pode levar a adaptaçóes e práticas culturais que auxiliem no incremento da resiliência ecológica.

O termo resiliência possui significados amplamente diferentes na literatura ecológica, por vezes relacionada ao conceito de estabilidade (Putman \& Wraten, 1984 \& Toft, 1986 apud Begossi, 1998). Para Gunderson e Holling (2000) resiliência seria a capacidade de absorver os distúrbios do ecossistema e ainda assim manter o sistema socioecológico íntegro, um processo que compreende as fases de exploração, conservação, liberação (destruição criativa) e reorganização (renovação), acompanhado de adaptações sociais nas comunidades envolvidas.

Debates em Ecologia Humana propóem que a diversidade de práticas de manejo dos recursos naturais baseadas no conhecimento ecológico local, e os mecanismos sociais por trás das práticas, identificadas e organizadas, venham a auxiliar na construção de resiliência e sustentabilidade nos sistemas socioecológicos - gestão conhecida como Manejo Adaptativo (Folke et al., 1998; Berkes \& Folke, 1998; Gunderson \& Holling, 2000).

Folke et al. (1998) delinearam 13 práticas de manejo baseadasnoconhecimentoecológicolocal:(1)Monitoramento de mudanças no ecossistema e na abundância de recursos; (2) Proteção total de certas espécies; (3) Proteção de estágios vulneráveis na história de vida das espécies; (4) Proteção de habitats específicos; (5) Restriçóes temporais de captura; (6) Manejo integrado de múltiplas espécies; (7) Rotação de recursos; (8) Manejo sucessional; (9) Manejo de manchas de paisagem; (10) Manejo de Bacias; (11) Gestão de processos ecológicos em escalas múltiplas; (12) Responder e manejar pulsos e surpresas; e (13) Nutrir fontes de renovaçáo.

Ainda, Folke et al. (1998) destacam quatro mecanismos sociais que devem existir detrás das práticas de manejo, para construção de resiliência. São eles:

(a) Geração, acumulação e transmissão do conhecimento ecológico: Re-interpretar sinais de aprendizado; Reviver o conhecimento local; Transmissores de conhecimento/folclore; Integração de conhecimento; Transmissão de conhecimento intergeracional; Transferências geográficas de conhecimento;

(b) Estrutura e dinâmica das instituiçôes: Diversidade de expertise/especialistas; Avaliação comunitária; Instituiçõos transescalares; Tabus e regulaçóes; Sanções culturais e sociais; Mecanismos copiadores/ resposta em curto prazo às surpresas; Habilidade de reorganizar sob circunstâncias de mudança; Instituições incipientes;

(c) Mecanismos de internalização cultural: Rituais, cerimônias e outras tradições; Codificar ou redigir como um anteprojeto;

(d) Visão de mundo e valores culturais: Compartilhamento, generosidade, reciprocidade, redistribuição, respeito, paciência, humildade.
Folke et al. (1998) ainda pensaram em sete princípios para que adaptatividade e resiliência sejam construídas em um sistema socioecológico:

- Usar práticas de manejo baseadas no conhecimento ecológico local;

- Desenhar sistemas de manejo que "fluam com a natureza";

- Desenvolver conhecimento ecológico local para entender ciclos naturais e eventos imprevisíveis;

- Aumentar mecanismos sociais para se construir resiliência;

- Promover condiçóes para auto-organização e aprendizado institucional;

- Redescobrir o manejo adaptativo;

- Desenvolver valores consistentes compatíveis sistemas socioecológicos resilientes e sustentáveis.

\subsection{Procedimentos de coleta e análise de dados}

Para a execução deste trabalho foram realizadas cerca de 70 visitas à área de estudo, entre 2006 e 2010. Após um período de aproximação com a comunidade e aceitação da pesquisa por eles, foram aplicadas entrevistas semiestruturadas (Viertler, 2002) com 20 residentes jovens e adultos, entre os meses de agosto e outubro de 2008 (aproximadamente $9 \%$ da população total, $17 \%$ da população adulta da Ilha Diana), com base na informação de 240 residentes. Só não foi possível majorar este número devido à resistência de muitos residentes em contribuir com esta pesquisa ou à dificuldade de se encontrar alguns moradores durante o horário comercial. Verificamos, entretanto, a constante repetição de opinióes nos resultados obtidos, o que nos leva a crer que o universo amostral foi satisfatório com a intenção desta pesquisa em se realizar uma análise prioritariamente qualitativa. Questóes fechadas foram, de maneira geral, utilizadas para o levantamento dos dados socioeconômicos e questóes abertas, principalmente, para analisar de forma qualitativa os aspectos socioecológicos da cultura caiçara, práticas tradicionais de manejo dos recursos pesqueiros e as transformações neste território.

Para iniciar a investigação estabelecemos um quadro amostral prévio que foi dividido equitativamente entre gêneros: 10 homens e 10 mulheres distribuídos em três faixas etárias pré-estabelecidas: Classe I (entre 16 e 35 anos), Classe II (36 a 55 anos) e Classe III (mais de 56 anos) - conforme esquematizado na Tabela 1. Optou-se por entrevistar os indivíduos a partir dos 16 anos, pois a partir desta idade já é possível ingressar no mercado de trabalho formal e, portanto, a partir desta idade os entrevistados já poderiam opinar a respeito de seu futuro profissional. No entanto, a idade do entrevistado mais jovem foi de 18 anos.

Do total de entrevistados, cinco pertenciam à Classe I, oito pertenciam à Classe II e sete pertenciam à Classe III. A idade das mulheres entrevistadas variou entre 18 a 90 anos e a dos homens variou entre 30 a 73 anos.

O entrevistado mais idoso foi a primeira moradora da Ilha Diana, com 90 anos, e com ela foi realizada uma entrevista aberta (Viertler, 2002) sobre as transformaçóes da Ilha e questóes da pesca. Esta entrevista foi registrada em gravador digital e teve a duração de três horas. 
Tabela 1. Caracterização da população amostral.

Table 1. Characterization of the sample population.

\begin{tabular}{|c|c|c|c|}
\hline Classes de idade & Classe I (16 a 35 anos) & Classe II (36 a 55 anos) & Classe III (mais de 56 anos) \\
\hline \multirow{2}{*}{ 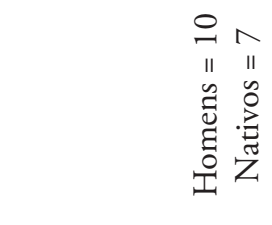 } & Pescador $=0$ & Pescador $=1$ & Pescador $=2$ \\
\hline & Não pescador=2 & Não pescador=3 & Não pescador=2 \\
\hline $\begin{array}{l}\text { Total de homens } \\
\text { por idade }\end{array}$ & 2 & 4 & 4 \\
\hline \multirow{3}{*}{ 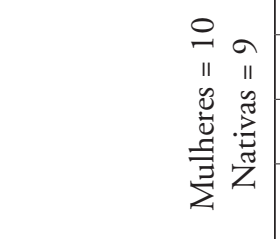 } & & & \\
\hline & Pescadora $=0$ & Pescadora $=1$ & Pescadora $=1$ \\
\hline & Não pescadora $=3$ & Não pescadora $=3$ & Náo pescadora $=2$ \\
\hline $\begin{array}{l}\text { Total de mulheres } \\
\text { por idade }\end{array}$ & 3 & 4 & 3 \\
\hline $\begin{array}{l}\text { Total de } \\
\text { entrevistados por } \\
\text { idade }\end{array}$ & 5 & 8 & 7 \\
\hline
\end{tabular}

Dos 20 entrevistados, apenas duas mulheres e três homens ainda exerciam atividade de pesca $(25 \%$ dos entrevistados e $42 \%$ dos pescadores ativos na Ilha Diana). A estes foi aplicado um questionário específico que buscou informaçôes qualitativas e quantitativas relacionadas à pesca a fim de investigar práticas locais de manejo.

As entrevistas semiestruturadas não foram gravadas em áudio a pedido da comunidade, portanto foram registradas manualmente. As entrevistas duraram de uma a três horas. Para preservar o anonimato dos entrevistados, estes receberam apenas a primeira letra do nome, gênero e foi citada sua idade na época das entrevistas em 2008.

As transcriçóes ao longo do texto foram selecionados de modo que pudessem melhor identificar os elementos investigados. Não foi objetivo deste trabalho realizar uma análise quantitativa das práticas e mecanismos identificados, pois considerando a complexidade do tema, uma análise desta natureza poderia subestimar resultados cuja singular ocorrência já torna-se significativa em termos socioecológicos.

Deste modo, os aspectos da cultura caiçara relacionados à ancestralidade, auto-reconhecimento, relações familiares, religião e organização social, foram identificados de acordo com Diegues (1983), Begossi (1998) e Presidência da
República do Brasil (2007). Práticas de manejo pesqueiro baseadas no conhecimento ecológico tradicional (itens enumerados) e os mecanismos sociais atrelados a elas (identificados por letras) foram sistematizados de acordo com Folke et al. (1998), conforme item 2.2. As transformaçóes na pesca foram identificadas e suas conseqüências foram discutidas com base nos princípios de adaptatividade e resiliência em sistemas socioecológicos propostos por Folke et al. (1998).

\section{RESULTADOS}

A comunidade da Ilha Diana foi formada a partir de quatro núcleos familiares que na década de 30 foram remanejados do Saco da Embira, na antiga Vila do Itapema e atual Base Aérea de Santos (Distrito de Vicente de Carvalho, Guarujá - SP), para o local atual devido aos bons aspectos da pesca do estuário santista neste período. Destaca-se a fala da moradora mais antiga da Ilha Diana, D, mulher, 90 anos, que nasceu no Saco da Embira e declarou habitar na Ilha Diana há 60 anos, aonde chegou com seu marido, sua mãe e seu padrasto: "Depois que vieram os moradores para cá... eu sou a primeira moradora da Ilha Diana. Uns já nasceram na Ilha, outros velhos já morreram. Eu tinha uma casa que foi da 
minha mãe, que a Base pagou... indenizou todas as pessoas da Ilha, mesmo com a casa caindo em cima das pessoas...".

$\mathrm{M}$, homem, 73 anos, conta por que a pesca foi o motivo que o levou a morar na Ilha Diana: "Tenho 73 anos de Rio Diana, me criei na outra margem do rio com meu tio e minha avó (local ocupado hoje pela empresa portuária). Na Ilha mesmo, moro há uns 40 anos ... Pro meu ramo de trabalho, aqui é bom, porque pode deixar a embarcação aí. Em outro lugar não, não pode deixar a rede porque pegam... ai é mais tranquilo. É calmo, não há desconfiança um do outro, tudo é familia, parente, e os que entraram também fizeram amizade". Destaca-se nesta transcrição a organização social da pesca, as relaçōes de parentesco, respeito e reciprocidade, fatores tidos como importantes mecanismos sociais de visão de mundo e valores culturais (Mecanismo $d$ do item 2.2) e tidos como característicos das comunidades caiçaras.

$\mathrm{Na}$ Ilha Diana, o seu relativo isolamento geográfico perdurou até a década de 1980, quando foi iniciado o serviço de balsas que facilitou o acesso ao centro de Santos e Vicente de Carvalho (com tempo de travessia em 20 e 10 minutos respetivamente). Os habitantes, de maneira geral, movimentam-se diariamente a estes dois centros urbanos para executar tarefas rotineiras, como ir ao trabalho, bancos, compras, médicos e farmácias.

Dos 20 entrevistados, apenas quatro não eram nativos da Ilha Diana (uma mulher e três homens), sendo que dois deles eram de outras cidades costeiras do litoral de São Paulo e os demais de outros estados brasileiros. Os quatro permaneceram residindo na Ilha Diana por estarem casados com moradores nativos. De acordo com Diegues (1983), muitas regras e práticas da cultura caiçara são baseadas em relaçóes de parentesco. A aceitação de pessoas não nativas apenas mediante o casamento com um nativo, como verificado com os resultados obtidos, é um forte mecanismo de exclusão de agentes externos, fator tido como um importante subsídio à resiliência socioecológica. Segundo Folke et al. (1998) a exclusão de demais usuários é uma mecanismo que versa sobre as sançóes culturais e sociais inerentes à estrutura e dinâmica das instituiçôes (Mecanismo $b$ do item 2.2) e que favorece a resiliência.

Dez entrevistados declararam que o pai trabalhara como pescador e oito declararam que a mãe fora pescadora. Dentre estes, sete possuíam ambos, pai e mãe, pescadores. Relataram ter aprendido a pesca com os pais, tios e avós, o que reforça a proximidade entre as relações familiares e a pesca nesta comunidade. Verifica-se a ocorrência do mecanismo social de geração, acumulação e transmissão do conhecimento ecológico (Mecanismo $a$ do item 2.2) relativo à pesca, através das geraçôes.

Quando questionados sobre sua ancestralidade, oito entrevistados declararam de forma espontânea ser descendentes de caiçaras. Também foi mencionada a ascendência italiana ( 7 citaçóes), portuguesa (4 citações), indígena (3 citaçôes), entre outras. Ao fazer a mesma questão de forma induzida, 18 entrevistados responderam que se consideravam caiçaras. A comunidade toma um passo importante para o reconhecimento de seu território quando se autodeclara caiçara. Este auto-reconhecimento atende aos pressupostos da PNPCT (Decreto Federal No 6.040), o que reforça a caráter tradicional desta comunidade e a necessidade da garantia deste território como condição para manutenção desta cultura no sistema.

Como características da cultura caiçara, os entrevistados consideram que: o povo caiçara é aquele que vive no mar e do mar, dependem da pesca, há forte união familiar, possuem costumes, tradiçôes e modos de vida próprios: " $A$ vida caiçara é seguir o ritmo dos parentes, aquele modo de vida, os mesmos costumes, a relação de educaçâo, é dividir a comida" (E, mulher, 30 anos). Tal afirmação reforça as relaçóes de parentesco, respeito e reciprocidade (Mecanismo $d$ do item 2.2) da cultura caiçara.

Ainda com relação ao Mecanismo d do item 2.2, novamente destaca-se a visão de mundo e os valores culturais presentes na fala de A., homem, 63 anos, natural de IguapeSP, um dos entrevistados cujos pais possuíam forte ligação com a agricultura, atividade tipicamente caiçara de acordo com Diegues (1983), porém inviável na Ilha Diana, devido à sua localização sobre o manguezal: "Me considero caiçara porque nasci em Iguape. Caiçara lá e aqui. Porque tá na beira de mar, todo mundo que nasce na beira do mar é caiçara... em São Sebastião... É pão, com banana, com farinha... Caiçara é o seguinte, porque mora na beira do mar, gosta de pescaria, de comer peixe, em fim de estória, é tudo, é a coisa melhor da vida é ser caiçara. Se você estica a rede pega peixe, tarrafa pega camaráo, pega também tainha, qualquer tipo de peixe. Pesquei, criei meus filhos à custa de pescaria, tudo à custa de crustáceo, camaráo, ostra, caranguejo, marisco. Parei de pescar porque a pescaria não dá mundo. Pesquei um ano em parelha com arrastão em barco de pesca, ficava duas semanas, peguei trovoada, tudo... É uma vida triste, uma vida muito sofrida a do pescador ... Comecei a pescar em Iguape, tainha de rede, na água doce pescava traira, pitu, cascudo, manjuba. Comecei a pescar porque precisava... não tive infância, eu tenho minha inteligência que Deus me deu..." Percebe-se sentimentos antagônicos na fala do entrevistado, onde a vida caiçara é tanto percebida de modo positivo, quanto com aspectos de adversidades inerentes à atividade pesqueira - incerta, arriscada, imprevisível - dicotomia amplamente descrita por Maldonado (1986).

De Iguape veio a tradição de cultuar o Bom Jesus e há na comunidade uma capela em homenagem ao Santo, que há oito anos teve seu nome adaptado para "Bom Jesus da Ilha Diana”. Seu dia é comemorado em 6 de agosto com uma grande festa existente há 54 anos. Atualmente a organização da festa está a cargo da Associação de Melhoramentos da Ilha Diana (única organização não-governamental comunitária existente), que recebe apoio da Prefeitura de Santos e do novo empreendimento portuário.

Ao questioná-los sobre o significado das comemoraçóes do dia do Bom Jesus, os entrevistados explicam que este dia representa fé, tradição, agradecimento pela pescaria e um momento de união da comunidade. Também foi mencionado que a festa traz aumento do número de visitantes, renda extra e uma mudança na pacata rotina. Alguns entrevistados demonstraram-se preocupados com a mudança de foco nesta tradição - lamentam que a fé existente na missa e na procissão de barco vem sendo substituída pelo foco comercial da festa e que há dois anos não ocorre a procissão de barco: " $A$ festa era para ser comemorada no dia do Bom Jesus, que é dia 6 de agosto, sem ter que ter rendimento. Tinha que ser no dia, 
sem pensar no rendimento. A gente pede muita ajuda para Ele, que os caiçaras pede, representa fartura. Pra gente que vive da pescaria, porque a gente pede ajuda para pescaria, para tudo!" $(\mathrm{N}$, homem, 43 anos). Mecanismos de internalização cultural como rituais, cerimônias e outras tradiçóes (Mecanismo $c$ do item 2.2) são mecanismos sociais que auxiliam na construção de resiliência, porém verifica-se que a perpetuação deste mecanismo na Ilha Diana vem sofrendo influência do mundo comercial e afetando a transmissão intergeracional do mesmo (Mecanismo $a$ do item 2.2).

Há também um grupo de mulheres espíritas que se envolvem intimamente na organização da Ilha Diana, nas reivindicaçóes junto ao porto privado, na gestão da escola e na organização das festas locais, inclusive na festa católica do Bom Jesus do Iguape. Verifica-se, portanto, uma relação harmoniosa entre religióes, fator de adaptatividade que possibilita a continuidade da tradição caiçara, oposto do que Begossi (1998) encontrou para a influência da religião evangélica na religiáo católica dos caiçaras.

Apesar de existir a Associação de Melhoramentos da Ilha Diana, esta se encontra desestruturada e desorganizada, fato que poderá enfraquecer os mecanismos de resiliência. Em estudo quantitativo realizado com 59 residentes, Stori et al. (2007) verificaram que $44 \%$ dos entrevistados participavam da Associação de Melhoramentos, e 78\% disseram ter interesse em discutir assuntos importantes para a Ilha Diana. De acordo com Begossi (1998), os caiçaras aparentemente não são politicamente organizados, ou apresentam organizaçôes recentemente desenvolvidas, diferentemente dos caboclos que são extremamente bem organizados e tem o desejo de defender seu modo de vida através da implantação de reservas extrativistas, o que seria mais sustentável: "Os caiçaras, devido à ausência de organizações políticas genuínas, e os cablocos, com suas celebradas organizaçóes de seringueiros, mostram dois padróes muito distintos de respostas a ameaças aos seus recursos naturais". Begossi (1998) defende o fortalecimento institucional dos caiçaras relativo ao manejo de recursos naturais para aumentar resiliência no sistema socioecológico e acredita que a participação em instituiçôes pode incluir mecanismos voltados à eficiência, estabilidade, resiliência e equidade.

É fato que a convivência neste pequeno território nem sempre é harmoniosa. A entrada do porto privado na vida desta comunidade também trouxe conflitos e desconfiança entre os residentes e vem causando um forte sentimento de insegurança aos habitantes da Ilha Diana: “... agora tá levantado, pescador nenhum pode pescar! Agora essa "Empresa Portuária" quer fazer aqui na frente da nossa Ilha uns tanques. Querem fazer ai, nós não vamos deixar, vai ter uma grande reunião dia 22, por isso que eu estou tratando da Ilha, porque eu sou a primeira que tem que estar lá no centro comunitário (reunião da Associação), porque senão a "Empresa Portuária" vai tomar nossa Ilha" (D, mulher, 90 anos). Os debates comunitários sobre a implantação do terminal portuário vêm promovendo uma habilidade da comunidade da Ilha Diana em se reorganizar sob esta circunstância de crise e pode promover o fortalecimento da instituição incipiente existente - a Associação de Melhoramentos da Ilha Diana (Mecanismo $b$ do item 2.2), este mecanismo social auxilia na construção de resiliência.
A pesca na Ilha Diana é desempenhada de forma artesanal, com pequenos barcos de madeira ou alumínio e utilizam motor de popa. Foram obtidos relatos descrevendo a manufatura das redes, as artes de pesca, a preparação da isca, as espécies mais capturadas, seus hábitos alimentares e comportamentais.

A pesca é realizada em diversos afluentes do sistema estuarino de Santos, bem como no canal principal do porto. Fato preocupante é que muitos desses locais onde ocorre a pesca são áreas historicamente contaminadas como o Porto da Alemoa, o Canal da Cosipa e a regiáo do terminal portuário de Barnabé-Bagres (Lamparelli et al., 2001; Abessa, 2008). Para Lamparelli et.al. (2001) o sedimento é uma das principais formas de exposiçẫo da biota aquática aos poluentes provocando efeitos tóxicos e/ou bioacumulação. De acordo com este relatório, alguns compostos encontrados nos sedimentos da regiáo da Baixada Santista estão, muitas vezes, acima das concentraçóes que podem causar efeitos tóxicos aos organismos aquáticos, (cádmio, chumbo, cobre, mercúrio, níquel, zinco), e alguns compostos se encontram acima do limite que provoca efeitos severos, como os hidrocarbonetos poliaromáticos (PAH) e diversas formas de hexaclorobenzeno (BHC), em especial, alfa, delta e gamaBHC. O relatório ainda apontou para uma redução da contaminação nos organismos avaliados (peixes, crustáceos e moluscos), em relação aos resultados de estudos anteriores para alguns metais (cádmio, chumbo, mercúrio), e alguns compostos orgânicos. Alguns grupos de contaminantes, como bifenilas policloradas (PCB), PAHs, dioxinas e furanos, que ainda não haviam sido estudados pela Companhia Ambiental do Estado de São Paulo (CETESB) em organismos aquáticos da região, apresentaram bioacumulação na biota analisada.

Destaca-se a capacidade de monitoramento de mudanças no ecossistema por outro entrevistado (prática de manejo número 1 do item 2.2), que percebe que a poluição no estuário santista diminuiu devido às novas técnicas de resposta a acidentes ambientais: "Antigamente caía muito óleo no mar, hoje a CETESB tá muito em cima, póe a barreira de proteçấo de óleo quando dá vazamento. Hoje tá cheio de marisco onde nunca criou marisco" (W, homem, 63 anos). De acordo com Lamparelli et al.(2001) de fato houve uma redução na emissão de poluentes industriais de Cubatão no sistema hídrico adjacente entre ao anos de 1984 e 1994 em 93\% para a carga orgânica (de 22.678 para 1.547 ton/ ano), em $97 \%$ para metais pesados (de 1.467 para 44 ton/ ano), em $92 \%$ para fluoretos (de 1.276 para 100 ton/ano), em $78 \%$ para fenóis (de 27 para 6 ton/ano) e em $90 \%$ para resíduos sedimentáveis (de 216 para 22 ton/ano), devido ao "Programa de Recuperação da Qualidade Ambiental de Cubatão" levado a cabo pela CETESB.

As principais espécies pescadas na Ilha Diana são robalo (Centropomus undecimalis e Centropomus parallelus), tainha (Mugil liza), parati (Mugil curema), carapeba (Diapterus rhombeus), bagre (Genidens genidens), camarão branco (Litopenaeus schmitti), caranguejo (Ucides cordata), siri (Callinectes danae), marisco (Mytella guyanensis e Mytella falcata) e ostra do mangue (importante fonte de renda para as mulheres) - tal fato demonstra que é prática neste território o manejo integrado de múltiplas espécies (Prática de manejo número 6 do item 2.2). De acordo com Stori et al. (2007), 
$42 \%$ dos 59 entrevistados declararam a pesca como fonte de renda principal ou secundária.

Com relação aos produtos da pesca os entrevistados contam que os destinam para a venda e alimentação de sua família: "Como e vendo para Santos, Perequê (Guarujá)... Meu filho já pescou robalo (3 unidades de $50 \mathrm{~kg}$ ) debaixo do pier da Alemoa... Quando dá muito robalo, a gente liga pra lá, 500 $\mathrm{kg}$ eles ficam, para levar para São Paulo para fazer sashimi" (W, homem, 63 anos). Em estudo prévio realizado com 59 residentes, Stori et al. (2007b) encontraram que 95\% dos entrevistados relataram consumir peixes do estuário, sendo que $10 \%$ deles comem todo dia e $48 \%$ comem pescados entre um e cinco dias na semana.

Com relação ao monitoramento de mudanças no ecossistema e na abundância de recursos (Prática 1 do item 2.2), registamos transcriçóes que demonstram:

- Monitoramento com relação às melhores condiçóes climáticas para a pesca e o comportamento dos peixes: "A diferençazinha que quando a água fica escura, água de chuva, é mais fácil, porque ele não enxerga muito a rede, água clara dificulta mais porque o peixe enxerga mais a rede. O peixe tem visão, na água de chuva é mais certeza de pegar mais peixe do que com água clara. Quem já está calejado de pescar, já sabe um pouquinho, ne?” (M, homem, 73 anos).

- Monitoramento referente à biologia reprodutiva dos pescados, como exemplificado por este relato sobre o camarão, associado à época do ano e à cor da água: "É peixe que vai criando aqui mesmo, camarão, tainhota, camarão branco que pega ai fora, é tudo daqui. Não tem pressão de água (profundidade) pra eles se criar, crescer. De 15 de dezembro em diante a água fica amarela, já muda de cor, começa a aparecer camarãozinho com 15 a 20 dias, com 1 mês ele já fica bom, já não tá tão profundo, até pegar a boca da barra e ir embora" (W, homem, 63 anos).

- Conhecimento sobre a arte de pesca a ser utilizada, a qual é escolhida de acordo com a hora do dia e da maré. Nota-se também monitoramento sobre o hábito alimentar da espécie relatada: "O camarão de engodo é à noite e o gerivá e o de tarrafa é de dia. Porque de dia ele fica mais no fundão, porque é mais escuro e de noite ele vai procurar comida na costeira" (M, homem, 73 anos).

A citação seguinte retrata o monitoramento da mudança nos estoques de camarão pela entrevistada (Prática 1), faz referência à proteção de estágios vulneráveis na história de vida das espécies (Prática 3) e à restriçōes temporais de captura (Prática 5): "Enfraqueceu depois que apareceu o geriva $e$ as tarrafa miúda, faz mais de 3 anos que apareceu. Vem tudo ali! Depois disso, pra cá... eu que não quero que essas crianças vai pescar. Se continuar assim, no futuro acaba tudo. Principalmente para quem pega camarão vivo. A não ser que eles comecem a proibir a pesca... aqui não tem proibição ... Devia proibir a pesca do camaráo para os bichinho crescer pelo menos uns 3 meses. Eles que sabem mais (os homens), a gente não sabe o tempo da cria. Só sei que um ano dá e só vai dar o ano que vem. Cada ano dá menos". (A, mulher, 56 anos).

Para o caranguejo outro entrevistado também demonstrou conhecimento acerca dos ciclos reprodutivos, do monitoramento da abundância deste recurso e se mostrou favorável à proteçáo de determinado estágio de vida desta espécie (Práticas 1 e 5): "Um dia depois da Lua Nova é quando eles começam a sair, ai anda dois, três dias, depois só na outra Lua. Andam duas, três luas ai só depois noutro ano. Aí só no braço... Ai isso não é vida pra mim... Tem bastante, andou sumindo, mas depois veio o defeso e apareceu muito mais. Faz 8 a 10 anos que tem o defeso... Concordo com o defeso, não atrapalha em nada, vendo bastante no Natal e Ano Novo" (W, homem, 63 anos).

Também foram constatadas práticas de rotação de recursos e de manejo sucessional (Práticas de manejo 7 e 8 do item 2.2), exemplificada pela transcrição seguinte, na qual o pescador utiliza seus conhecimentos para a escolha do local e estabelece medidas de manejo que possibilitem a recuperaçáo do estoque. "O programa já faz 1 dia antes. Você pesca um dia num lugar, noutro dia vai noutro lugar para descansar o lugar que você pescou antes" (M, homem, 73 anos).

Os pescadores declararam que não há regras entre eles e que a pesca no estuário é de livre acesso: "Regra não tem, mas quem vai primeiro leva vantagem. Porque pega o camarão sossegadinho e quem vem atrás pega menos, é que nem na feira" (N, homem, 43 anos). Neste sentido, regras locais para a exclusão de agentes externos aos locais de pesca e sistemas de gestão compartilhada com os demais usuários do estuário não foram observados. Apenas foi constatada a competição para encontrar o recurso antes que qualquer outro pescador do estuário. A falta deste mecanismo social na pesca (Mecanismo $b$ do item 2.2) que versa sobre as sançóes culturais e sociais inerentes à estrutura e dinâmica das instituiçôes enfraquece a resiliência.

Ainda com relação ao mecanismo social $a$ proposto por Folke et. al. (1998), foram encontradas na Ilha Diana três inovaçóes relacionadas a transferências geográficas de conhecimento. A primeira inovação diz respeito à introdução da "tarrafa italiana", a segunda relacionada à introdução do petrecho "gancho" e a terceira com a introdução do petrecho "gerival".

D., mulher, 90 anos, conta que além da tarrafa tradicional, ela também manufaturava a tarrafa tipo italiana: "Eu era a fazedeira da rede. Eu que fazia a rede para despescar! Aquilo quando jogava cobria tudo... era uma coisa linda. Agora tudo é feito de fábrica, né? Eu fazia cada tarrafa linda, à moda italiana, assim ó...”. Em comunicação pessoal com o professor Diegues, ele disse desconhecer este tipo de tarrafa, fato que reforça a peculiaridade na colonização da Ilha Diana e a influência destes imigrantes nesta cultura.

Destacamos a seguinte transcriçáo para exemplificar a segunda inovação, relacionada à introdução do "gancho" para a coleta de marisco no mangue, na década de 90: "Marisco tem dois jeitos, com o dedo e com o ganchinho também, ai não machuca o dedo. Pra te falar a verdade, quem trouxe o ganchinho pra cá foi o nordestino, há mais de 20 anos, aí tiravam bastante... um colega era bam bam bam (muito bom) no gancho" (M., homem, 73 anos).

A terceira inovação se deu há cerca de 15 anos com a introdução da arte de pesca gerival por pescadores migrantes do Estado de Santa Catarina. Este petrecho revolucionou a pesca artesanal de camarão e se tornou uma alternativa à 
tarrafa, uma adaptação que fez esta pescaria mais acessível a diversas categorias de idade e gênero: "Era tarrafa, faz 8 anos que passei para o gerivá. Eu era contra o gerivá. Porque quando a maré grande corre muito, o gerivá funciona mais e com a tarrafa é o contrário. Ficou fácil, todo mundo pesca" (N, homem, 43 anos).

\section{DISCUSSÁO}

Forman (1970, citado em Begossi, 1998) considera que uma inovação pode ser racionalmente recusada devido a características locais impróprias ao seu uso, muitas inovaçóes adequadas a condiçôes ambientais e benéficas à comunidade tendem a ser absorvidas pela mesma. De acordo com Begossi (1998), muitos comportamentos aprendidos de sociedades externas não são ecologicamente adaptativos e nem todos podem ser considerados como ecologicamente sustentáveis: os pontos chave são as possibilidades de se adquirirem novas variedades, da manutenção da variabilidade, para a adaptação a mudanças.

Para Begossi (1998), a perda de inovaçóes e conhecimentos pode ter efeito negativo sobre a resiliência ecológica. Neste caso, a extinção da arte de pesca "cerco fixo" no estuário de Santos, em virtude da proibiçáo do corte do mangue pelo Código Florestal - Lei Federal $N^{\circ} 4.771$ (Presidência da República do Brasil, 1965) e pelas normas de segurança de navegação no Porto de Santos, ocasionou perda de conhecimento intergeracional desta arte na cultura caiçara (Mecanismo social $a$ do item 2.2). O cerco fixo se constituiu na arte de pesca mais seletiva já exercida, pois apenas permitia capturar espécies acima da idade reprodutiva. A extinção de artes de pesca baseadas no conhecimento ecológico tradicional, pela imposição de políticas públicas verticaldescendentes, somente colabora para a desestruturação do sistema e enfraquecimento da resiliência: "Você sabe por que eu gosto do mar? Tem que amar as águas que eu trago no sangue! Eu tirei minha carteira da capitania com 16 anos, eu nunca fiz trabalho pra ninguém. Eu só tenho pena e sinto falta do petrecho que eu tinha mais gosto na minha vida, o cerco. Só que não posso cortar as varas, o bambu. Enquanto deu pra cortar as varas de mangue, o melhor é o cerco. Se chove, se dá um vento forte, você fica em casa, depois vai lá e tá com o dinheiro na mão. Da idade de 12 anos pra cá trabalhei com o cerco. Faz uns 3 anos que eu não trabalho com cerco ... (já foi preso pela Polícia Ambiental por cortar taquara de mangue). Na média, o peixe aí acabou. Quando eu tinha 17, 18 anos, tinha muito cerco. Tinha desde o Ferry Boat da Bertioga até a ponte do Mar Pequeno (São Vicente), esse manguezal todo tinha cerco, uns 12. Você corta só varas de mangue, não vai cortar Siriúba porque vai estragar. Eu até fui ver o meu sistema de trabalhar, machadinho corta só escolhendo o que te serve, não pode ser muito grosso, nem muito fino, não pode ser torto... Porque eles confundem com a derrubada lá do Amazonas, mas aqui é diferente, não faz clareira, vai escolhendo... Nós chegamos a tirar aqui no cerco pescaria de uma tonelada em 1962, em dois dias pegamos duas toneladas, tainha adoidado que eu cansava de pegar tainha na mão, beleza pura!" (M, homem, 73 anos).

Os entrevistados atribuem o declínio dos estoques pesqueiros tanto à introdução, como à extinção de artes de pesca tradicionais, e também à poluição do estuário, às dragagens do porto, ao assoreamento das gamboas, alteração do curso dos canais do estuário, aumento no tráfego de embarcaçóes, concorrência do produto artesanal com grandes mercados varejistas e ao aterro do novo porto privado: "A diferença da produção é essa, é cortar rios, essa diferença nas marés, porque onde era fundo, passa a ser baixo ... Eu acho que o que devia parar, a "Empresa Portuária" está aterrando ali no Guarapá. Quantos metros cúbicos de água vão aterrar ali? Modifica. Então o peixe não cria mais com o barulho. O futuro vai acabar mesmo. Daqui mais uns 10 anos o pescador artesanal não deve existir mais, porque você vê, já tem bem pouco, pescador antigo já foi embora, morreram quase todos, tem bem pouquinho e o jovem não quer saber de pescar. A juventude agora é bem difícil. Antigamente nós se dedicava mais à luta, agora não, procuram as coisas mais fácil" (M, homem, 73 anos). Verifica-se através da fala do entrevistado que, junto com o declínio da pesca, também é perdida a diversidade de expertise (Mecanismo $b$ do item 2.2) devido ao falecimento de detentores do conhecimento ecológico e ao desinteresse dos jovens em dar continuidade a esta profissáo de características tão adversas, sempre muito imprevisível, arriscada e que, sobretudo, exige grande desempenho físico. A perda de conhecimento intergeracional (Mecanismo $a$ do item 2.2) diminui a variabilidade cultural, o que pode tornar a comunidade menos preparada para enfrentar mudanças, enfraquecendo a resiliência do sistema local.

$\mathrm{Na}$ transcrição de outra entrevista verifica-se que a pesca já não constitui mais a base econômica desta sociedade, que prefere incentivar seus jovens a seguir um caminho mais seguro para obter recursos financeiros: "Mudou o modo de vida das pessoas, de pensar, antigamente vivia mais da pesca, hoje o pessoal quer mais trabalhar fora, a pesca tá acabando, não por si só, mas as empresas que tão acabando com a pesca, construindo cais, marina, porto. A pesca tá acabando mais por causa das empresas, dragagem daqui, dragagem de lá, não há peixe que suporte. A pesca tá bem fraca. Há 15 anos atrás era bastante fartura. E o mercado de venda tá bem fraco. Há 15 anos tinha para quem vender. Tá mudando a mente das pessoas para ter renda fixa. Porque a pesca não tem. Não tem para quem vender. Antigamente tinha gente no mercado, hoje em dia não tem mais. Para comprar camarão, nada. Acredito que seja mais por causa desse negócio de importação. O pessoal do mercado de Santos busca no CEASA (Centrais de Abastecimento S/A) para revender. Não compra mais daqui"(V, homem, 37 anos). Acreditamos que a poluição do estuário exerceu forte impacto na comercializaçáo do pescado capturado na Ilha Diana, pois fez com que o produto explorado pelos caiçaras perdesse valor. Tendo em vista os projetos de expansão do complexo industrial-portuário de Santos, fica difícil vislumbrar o retorno às condiçóes de pesca de outrora. Hoje os pescadores apenas pescam quando estão desempregados, demonstrando que o mundo comercial passa a predominar na Ilha Diana.

Quando questionados sobre o que poderia ser feito para melhorar a pesca no estuário, as declarações foram bastante pessimistas em virtude das futuras projeçōes, tanto pela implantação do empreendimento portuário vizinho à comunidade, quanto de outros projetos de expansão portuária, do futuro aeroporto do Guarujá e da indústria do petróleo: "Nos meus conhecimentos não vai ter mais recuperação. Não acredito mais porque é muito difícil, porque daqui uns dias 
esses manguezais aí vão ser todos derrubados, já tem as empresas todas de olho, já tem o projeto aí, tem Ilha Barnabé e Ilha dos Bagres. Vai acabar.. já pensou aquilo ali com aterro em tudo aquilo ali? Não tem mais como ser antigamente. Também não é só aqui em São Paulo, é todo lugar! Vai evoluir. A evolução para uns, é o prejuizo para outros" (M, homem, 73 anos).

Os entrevistados demonstraram estar conscientes de que o modo de vida da Ilha Diana será fortemente impactado pelos novos projetos de desenvolvimento do Porto de Santos e buscam uma forma de adaptar seu modo de vida nesse novo paradigma: "Acho que vai ser tumultuado. Acho que daqui 3 ou 4 anos vai tirar o sossego daqui. Em relação de comércio vai ser bom, mas em relação de sossego, tranquilidade, a comunidade tem que estar disposta a perder isso. Tem que estar se preparando para isso. E por ser uma comunidade caiçara, tinha que ter mais preservaçáo sobre meio ambiente, sossego, porque vai mudar tudo" (E, mulher, 30 anos). Verifica-se no depoimento da entrevistada uma consciência de que a cultura caiçara e o ambiente devem ser valorizados, configurando novamente em uma habilidade de reorganização sob circunstâncias de mudança (Mecanismo $b$ do item 2.2), fator que confere adaptatividade e auxilia na construção de resiliência.

De acordo com Begossi (1998), uma maior flexibilidade econômica pode representar maior probabilidade de "sobrevivência cultural" e, aparentemente, as comunidades neotradicionais beneficiam-se dessa flexibilidade. $\mathrm{O}$ aspecto importante é que tal flexibilidade cultural é normalmente relacionada a comportamentos culturais que podem elevar a resiliência ecológica, como as técnicas (tradicionais e neotradicionais) de manejo dos recursos e a habilidade de manejar uma mistura de culturas, na qual as tradiçóes culturais sobrevivem juntamente com inovaçóes.

Berkes e Folke (1994, citado em Folke et al. 1998) já propunham que haveria considerável evidência do capital cultural relativo à sustentabilidade do uso do recurso e à manutenção dos ecossistemas resilientes. De acordo com Begossi (1998), pode ser argumentado que grupos que apresentam contribuiçóes de duas ou mais tradições culturais, como são os casos dos caiçaras e dos caboclos, têm um capital cultural mais rico e uma gama mais ampla de opçóes adaptativas. Assim, tais grupos podem possuir maior flexibilidade cultural do que as sociedades das quais se originaram. A cultura é adaptativa porque, entre outros aspectos é variável e flexível. A variabilidade ou a diversidade (de genes, espécies ou cultura) é base para a sobrevivência $\mathrm{e}$ permite às comunidades se adaptarem a mudanças ambientais.

A comunidade da Ilha Diana habita neste local há mais de oito décadas e teve seus primeiros habitantes originados de outra localidade deste mesmo território de pesca no estuário de Santos-SP. Na atualidade, a deficiência da pesca em quantidade e qualidade, e a ausência da agricultura como fonte alternativa de renda, restringem a capacidade adaptativa neste território. Com o declínio da qualidade ambiental no estuário e com a demanda pela implantação de projetos de expansão portuária e apoio à indústria de petróleo, os habitantes da Ilha Diana buscam se inserir no mundo comercial.

Pudemos verificar que os entrevistados possuem organização social historicamente ligada à pesca e que ocuparam este território e utilizaram de seus recursos naturais como condição para a reprodução da cultura caiçara: seus aspectos sociais, religiosos, ancestrais e econômicos. Os entrevistados demonstraram utilizar conhecimentos, inovaçóes e práticas gerados e transmitidos pela tradição, indo ao encontro do que preconiza a PNPCT - Decreto Federal No 6.040 (Presidência da República do Brasil, 2007). $\mathrm{O}$ auto-reconhecimento como caiçaras pelos entrevistados afirma a presença desta cultura neste território.

Os entrevistados demonstraram possuir de fato conhecimento ecológico a respeito dos recursos pesqueiros, de modo que foi possível identificar sete práticas de manejo elencadas por Folke et. al. (1998) no sistema socioecológico da Ilha Diana: Monitoramento de mudanças no ecossistema e na abundância de recursos; Proteção de estágios vulneráveis na história de vida das espécies; Proteção de habitats específicos; Restrições temporais de captura; Manejo de múltiplas espécies e integrado; Rotação de recursos e Manejo sucessional.

Ainda, foi possível identificar elementos dos quatro mecanismos sociais propostos por Folke et. al. (1998) que podem fortalecer resiliência. Tais como:

- Geração, acumulação e transmissão do conhecimento ecológico, principalmente observado nas geraçóes adultas que ainda exercem a atividade pesqueira, e também as transferências geográficas de conhecimento de artes de pesca (Mecanismo social $a$ );

- Sançóes culturais e sociais exemplificada pela exclusão de moradores que não apresentam relaçóes de parentesco, a existência de uma instituição incipiente (Associação de Melhoramentos da Ilha Diana) e a habilidade de reorganizaçáo sob circunstâncias de mudança, como nas tratativas com o empreendimento portuário para conquistar direitos fundamentais não providos pelo poder público (Mecanismo social $b$ );

- Rituais e cerimônias, representados principalmente pelo culto ao Bom Jesus da Ilha Diana (Mecanismo social $c$ );

- Respeito e reciprocidade, fatores tidos como importantes mecanismos sociais de visão de mundo e valores culturais, inerentes à cultura caiçara (Mecanismo social $d$ ).

Ainda, com relação ao mecanismo social $a$, foram encontradas na Ilha Diana três inovações relacionadas à transferências geográficas de conhecimento (tarrafa italiana, gancho e gerival), entretanto, observamos a perda de uma prática tradicional de pesca (cerco fixo) devido à imposição de políticas públicas vertical-descendentes. A comunidade da Ilha Diana mostrou flexibilidade em aceitar inovaçóes que permitam diversificar sua atividade econômica, no entanto é contestável se estas adaptaçóes favoreceram a resiliência do sistema. Acreditamos que a extinção de artes de pesca sustentáveis baseadas no conhecimento ecológico tradicional, pode enfraquecer a resiliência.

Ainda, constamos a perda de mecanismos sociais que poderão enfraquecer a resiliência do sistema local: Perda de conhecimento nas jovens geraçóes e a perda de expertise em decorrência do falecimento dos antigos moradores, levando 
à redução da variabilidade cultural (Mecanismo social $a$ ); Forte competição para obter o recurso pesqueiro e a falta de sançóes culturais e sociais para a exclusão de demais usuários pescadores (Mecanismo social b); Deslocamento no foco da festa em comemoração ao dia do Bom Jesus da Ilha Diana (Mecanismo social $c$ ), que apesar de ainda ser uma forte tradição, atualmente visa, sobretudo, obter benefícios econômicos.

\section{CONCLUSÓES}

Constatamos que os residentes na Ilha Diana possuem organização social histórica ligada à pesca e que, ocuparam este território e utilizaram de seus recursos naturais como condição para a reprodução da sua cultura: seus aspectos sociais, religiosos, ancestrais e econômicos - aspectos típicos da cultura caiçara. Os entrevistados demonstraram utilizar conhecimentos, inovaçóes e práticas gerados e transmitidos pela tradiçáo. $\mathrm{O}$ auto-reconhecimento como caiçaras, reafirma a presença desta cultura neste território.

Identificamos sete práticas de manejo baseadas no conhecimento ecológico local e quatro mecanismos sociais que configuram adaptatividade e favorecem a construção de resiliência neste sistema socioecológico. No entanto, o abandono da pesca e a conseqüente perda de conhecimento ecológico intergeracional poderá diminuir a resiliência neste sistema socioecológico.

O sistema socioecológico em questão pode buscar construir resiliência, seja pela inércia cultural de práticas tradicionais de manejo que busquem promover a recuperaçáo dos estoques pesqueiros, ou pela flexibilidade em absorver os impactos que estâo ocorrendo e se adaptar ao novo modo de vida. A promoção de resiliência no sistema socioecológico estudado dependerá da capacidade adaptativa a partir de práticas sustentáveis da comunidade caiçara.

Uma vez que o meio material da cultura caiçara encontra-se em processo de expropriaçáo pelos projetos de desenvolvimento econômicos no estuário de Santos, para que a cultura caiçara co-evolua com esse novo paradigma, indicase a promoção dos valores de seus bens imateriais, como como a identidade enquanto caiçaras, relaçóes familiares harmônicas, respeito, reciprocidade, fé, dentre outras manifestações da cultura caiçara. A inserção em projetos de turismo sustentável e valorização dos costumes tradicionais, parecem despontar como opçôes de produtos sustentáveis para a inserção da Ilha Diana no mundo comercial, de forma que a resiliência seja fortalecida. A crescente popularidade da Festa do Bom Jesus da Ilha Diana é a demonstração desta capacidade adaptativa, na qual a valorização das tradiçóes é um produto que possibilita sua inserção no mundo comercial juntamente com a valorização da cultura. A comunidade da Ilha Diana demonstrou flexibilidade em diversificar sua atividade econômica, no entanto, apenas um acompanhamento a longo prazo poderá responder se estas adaptaçôes favorecerão a construção de resiliência.

Desta maneira, a habilidade dos habitantes da Ilha Diana em interagir com o restante da sociedade, como observado, e a flexibilidade de tais interaçóes são fatores que podem elevar a capacidade para enfrentar mudanças. Esta habilidade na reorganização diante de circunstâncias de mudança poderá contrabalancear os aspectos negativos do processo de transformação e crise, promovendo uma nova fase do ciclo do manejo adaptativo: a reorganização do sistema e o encontro de um novo patamar em sustentabilidade.

Para tal, recomenda-se que sejam fortalecidos os mecanismos sociais e que sejam valorizadas as práticas de manejo baseadas no conhecimento ecológico local para responder aos eventos imprevisíveis, tais como os impactos dos futuros projetos de desenvolvimento planejados para o território. Ainda, recomendamos que os residentes promovam condiçóes para auto-organização pressionados pelas iminentes mudanças e que ocorra o fortalecimento da instituição existente (Associação de Melhoramentos), o redescobrimento do manejo adaptativo e o desenvolvimento de valores compatíveis com sistemas socioecológicos resilientes e sustentáveis.

\section{BIBLIOGRAFIA}

Abessa, D.M.S.; Carr, R.S.; Sousa, E.C.P.M.; Rachid, B.R.F.; Zaroni, L.P.; Pinto, Y.A.; Gasparro, M.R.; Bícego, M.C.; Hortellani, M.A.; Sarkis, J.E.S; Muniz, P. (2008) - Integrative Ecotoxicological Assessment of a Complex Tropical Estuarine System. In: Hoffer (ed.), Marine Pollution: New Research, pp.125-159, Nova Science T.N. Publishers Inc., New York, U.S.A. ISBN 1604562420

Adams, C. (2000) - Caiçaras na Mata Atlântica: pesquisa cientifica versus planejamento e gestão ambiental. 336p., Annablume, São Paulo, SP, Brasil. ISBN: 85-74191019.

Afonso, C. M. (1999) - Uso e Ocupação do Solo na Zona Costeira do Estado de São Paulo: Uma Análise Ambiental. 186p., Annablume, FAPESP, 1ª Ed., São Paulo, SP, Brasil. ISBN: 85-74190950

Begossi, A. (1998) - Resilience and neo-traditional populations: the caiçaras (Atlantic Forest) and cablocos (Amazon, Brazil). In: F. Berkes \& C. Folke (eds.), Linking Social and Ecological Systems: Management Practices and Social Mechanisms for Building Resilience, pp.129-157, Cambridge University Press, Cambridge, U.K. ISBN: 9780521785624.

Berkes, F.; Folke, C. (1998) - Linking Social and Ecological Systems: Management Practices and Social Mechanisms for Building Resilience. 414p., Cambridge University Press, Cambridge, U.K. ISBN 9780521785624.

EMBRAPORT (Empresa Brasileira de Terminais Portuários), (2003) - Terminal Portuário Embraport - Relatório de Impacto Ambiental. MKR Tecnologia, Serviços, Indústria e Comércio Ltda. Não publicado.

Diegues, A.C.S. (1983) - Pescadores, camponeses a trabalhadores do mar. 287p., Ática, São Paulo, SP, Brasil. ISBN: 858732

Folke, C.; Berkes, F.; Colding, J. (1998) - Ecological Practices and Social Mechanisms for Building Resilience and Sustainability. In: Fikret Berkes \& Carl Folke (org.), Linking Social and Ecological Systems: Management Practices and Social Mechanisms for Building Resilience, 414p., Cambridge University Press, Cambridge, U.K. ISBN: 9780521785624 
Gunderson, L.H.; Holling, C.S. (2000) - Panarchy: Understanding Transformations in Human and Natural Systems. 508p., Island Press, Washington, D.C., U.S.A. ISBN: 1559638575

IBGE (2010) - Censo Populacional 2010: Cidades@ Informaçôes sobre os Municipios Brasileiros. IBGE- Instituto Brasileiro de Geografia e Estatística., Rio de Janeiro, RJ, Brasil. Disponível em http://www.ibge.gov.br/cidadesat/ topwindow.htm?1

Lamparelli, M.L.; Costa, M.P.; Prósperi, V.A.; Bevilácqua, J.E.; Araújo, R.P.A.; Eysink, G.G.L.; Pompéia, S. (2001) Sistema Estuarino de Santos e São Vicente. 178p., Relatório Técnico CETESB, São Paulo, Brasil. Disponível em: http://www.cetesb.sp.gov.br/Agua/relatorios/rel_sist_ estuarino/relatorio.zip.

Maldonado, S. (1986) - Pescadores do Mar. 80p., Editora Ática. São Paulo, SP, Brasil. ISBN: 8508011628

Marques, J.G.W. (2001) - Pescando Pescadores: Ciência e Etnociência em uma Perspectiva Ecológica. 258 p., 2a . Ed., Núcleo de Apoio à Pesquisa sobre Populações Humanas e Áreas Úmidas Brasileiras,USP, São Paulo, SP, Brasil. ISBN: 85-87304054.

Ministério do Meio Ambiente (2002) - Agenda 21 Brasileira: Gestão dos Recursos Naturais. 187p., Brasília, DF, Brasil.

Prefeitura Municipal de Santos (1998) - Lei Complementar No 311 de 24 de novembro de 1998. Institui o Plano Diretor de Desenvolvimento e Expansão Urbana do Município de Santos e dá Outras Providências.

Presidência da República do Brasil (1965) - Lei No 4.771 de 15 de setembro de 1965 - Institui o Código Florestal Brasileiro $e$ dá outras providências. Publicado no Diário Oficial da Uniāo de 16 de setembro de 1965. Disponível em: http:// www.planalto.gov.br/ccivil_03/leis/L4771.htm

Presidência da República do Brasil (2007) - Decreto No 6.040 de 7 de fevereiro de 2007 - Institui a Politica Nacional de
Desenvolvimento Sustentável dos Povos e Comunidades Tradicionais. Publicado no Diário Oficial da União de 8 de fevereiro de 2007, Seção 1, páginas 316 e 317. Brasília, DF, Brasil. Disponível em: http://www.planalto.gov.br/ ccivil_03/_ato2007-2010/2007/decreto/d6040.htm

Stori, F.T. (2010) - Adaptatividade e Resiliência no Sistema Socioecológico da Comunidade Caiçara da Ilha Diana, Municipio de Santos-SP. 239p., Tese de Doutorado, Programa de Pós-Graduação em Ecologia e Recursos Naturais, Universidade Federal de São Carlos, São Carlos, SP, Brasil. Disponível em: http://200.136.241.56/ htdocs/tedeSimplificado/tde_busca/arquivo. php? $\operatorname{cod}$ Arquivo $=4855$

Stori, F.T.; Souza, F.A.Z.; Gonçalves, P.S.F.; Hoffmann, P.P.; Maranho, L. A.; Davanso, M. B.; Marques, L.A.M; Souza, M.P.R.; Silva, L.G.; Lau, M.C.; Rojas, C.; Martinez, M.; Pinhata, J.M.W.; Tairum, C.A.; Mello, K. (2007) - Contributions to the study of the involvement of the caiçara community of Ilha Diana (Santos-SP) with the environmental licensing process of the privative port 'EMBRAPORT'. XVth International Conference of the Society for Human Ecology - Book of Abstracts, Rio de Janeiro, RJ, Brasil.

Tommasi, L.R. (1979) - Consideraçóes ecológicas sobre o Sistema Estuarino de Santos, São Paulo. Tese de Livre Docência, 489p., 2 volumes, Universidade de São Paulo, Instituto Oceanográfico, São Paulo, SP, Brasil.

Viertler, R.V. (2002) - Métodos antropológicos como ferramenta para estudos em Etnobiologia e Etnoecologia. In: M.C.M. Amorozo, L.C. Ming, \& S.P. Silva (Orgs.), Métodos de Coleta e Análise de Dados em Etnobiologia, Etnoecologia e Disciplinas Correlatas. 204p., Anais do Seminário de Etnobiologia e Etnoecologia do Sudeste. Org: Rio Claro: UNESP/CNPq. ISBN: 85-902432-1-4. 1. 